\title{
A comparative study regarding to physical and calorific properties of briquettes from vegetable biomass
}

\author{
Cosmin Spirchez ${ }^{{ }^{*}}$, Aurel Lunguleasa ${ }^{1}$, and Cătălin Croitoru ${ }^{2}$ \\ ${ }^{1}$ Transilvania University of Brasov, Wood Processing and Design Wooden Product Department, 29 Street Eroilor, Brasov, Romania \\ ${ }^{2}$ Transilvania University of Brasov, Engineering Materials Department, 29 Street Eroilor, Brasov, Romania
}

\begin{abstract}
The paper makes a comparison between four types of briquettes: first was wheat and rapeseed briquettes, second was wheat briquettes (batch 2018), third was wheat briquettes (batch 2017), and fourth was lucernes briquettes, from the point of view of the physical and energetic characteristics, in order to choose the best ones and their corresponding market. The main properties studied are the density and moisture of the briquettes, physical properties, and also calorific power and ash content as energetic properties. Research results show that wheat and rape briquettes have had high calorific value but low density, compared to other types of briquettes. A general conclusion rise from whole paper, respectively the vegetable biomass is a renewable material and briquettes from it remains the best option of combustible materials.
\end{abstract}

\section{Introduction}

The biomass is the biodegradable part of the vegetal products, wastes and agricultural residues, including the vegetal and animal substances, as well as the biodegradable part of industrial and / or urban wastes.

The biomass represents the most abundant renewable resource on the planet. This includes absolutely all the organic matter, obtained through metabolic processes of live organisms.

The biomass is a renewable energetic source by the fact that, it increases year by year, it is widely spread worldwide and it has low costs in comparison to the fossil fuels. The biomass resources, the fuel material is made of, may include the wood and wooden wastes, agricultural cereals and wastes resulted from their production, municipal wastes, animal dejections, wastes from food processing, aquatic biomass and algae. The biomass is one of the renewable sources forms which may be converted in solid, liquid and gaseous fuel, and which may generate energy as heat through its burning, as well as electrical energy through the industrial conversion processes, individually or in combination with fossil coal [1].

The biomass in vegetal form is a complex compound and differs from a vegetal species to other. This comprises all the forms of vegetal materials, which grow on the terrestrial surface, in water or on water, as well as other substances by biological development or degradation.

The biomass is environmentally friendly and a neutral energy against the $\mathrm{CO}_{2}$ emissions. The carbon dioxide is absorbed by the plants during growth and forms a closed circle of entering and continuity, because the quantity of $\mathrm{CO}_{2}$ which was absorbed by the vegetal part (either the one formed by vegetal plants, shrubs or trees) during the growth will be equal the same quantity which will be released during the burning out processes or of discomposure in nature under the action of biopests. The biomass may be used in the combustion processes and in most of cases it does not require very high investments as it is necessary for the production of hydro-electrical, solar, wind and geothermal energy[2].

At the worldwide level, according to the latest research in the field, there are highlighted preoccupations in the field of biomass use on energetic purposes. Romania has a potential of $60 \%$ in energy production from the existing sources of biomass. Also, in the same manner, it might be said that Romania has a surface of 6.3 million ha, which represents $27 \%$ of the surface of the whole existing territory. The resources from biomass, at the present, represents the raw material resulted from the wood processing, from agriculture, municipal wastes and animal. All this raw material resulted from the wood processing, from agriculture, municipal wastes and animal dejections. All this raw material recycled and used becomes a valuable material to produce energy, heat and a bio-fuel [3].

The biomass differs from the other forms of renewable sources forms by the fact it represents 0 resourceful raw material which can be easily transported due to its solidity, and it can be processed through different processes of conversion in gaseous, liquid or solid fuels. The biomass is divided in 4 categories described in the normative SR EN 14961-1:

- Forest production: wood, wastes from wood cutting, sawdust, trees, shrubs, splints, bark, resulted from the forest exploitation and trimming; 
- Wastes: resulted from the agricultural production, from agricultural processes, cereal wastes, organic urban wastes;

- Energetic cereals: crops from short-term processing, crops of starch (corn, wheat and barley), sugar crops (sugar cane and sugar beetroot), fodder crops (grass, alfalfa and clover), oligeneous crops (sun flower, soy, saffron);

- Aquatic plants: algae, water weeds, water hyacinth, reed and rush;

The wooden biomass comes from the wood resulted after trimming the tree branches, which cannot be used industrially, from wood quantities which is due to be processed, from forests and wood processing. Practically the forest exploitation starts by cutting the wood in the forest, trimming the branches and removing the roots, after which there is the transportation operation and the storage within the processing plants, the place where the real sorting and classification on quality groups of the wood is performed, all of this representing approximately $10 \%$ wooden wastes [4].

Briquettes and pallets are products made from wooden wastes such as mince, sawdust or / and agricultural wastes. The quality of the briquettes depends on the compression endurance and their density, having a caloric power higher as they are more compressed. The briquettes are the most advantageous heating methods of dwellings, because they are cheap, they may be used in stoves and central heating, with an intense burning without leaving much ash, they are easily transported and stored.

At the present, it is noticed that the used of biomass is in a continuous increase. This increase is materialized by the usage directions of biomass and the products resulted by biomass processing, separated in material to produce biogas and biofuel.

The wooden crops are differentiated, according to the research, in net biomass quantity of material available through the following four factors: quantity of solar energy, quantity of biomass intercepted by biomass, the efficiency of the photosynthetic conversion in energy, loss of biomass by exploitation. Besides the solar energy, obtaining some higher crops of primary biomass and more qualitative, is conditioned by several factors, such as: internal - genetic factors (species, variety, hybrid), which have a critical role in the accumulation capacity of biomass, external factors (environment factors, technological factors) [5].

Using the wood as energy source has increased very much during the last decades in all the counties in developing process, but this resource has not been exploited as durable, but through massive and uncontrollable exploitations of the forest areal. The biomass potential could be doubled only by systematic recovery of all the organic origin waste (household, industrial, agricultural, forest).

Romania is a country with high potential in the renewable energy sources field and that is in producing energy from biomass, one of the reasons for the increase of this field being the raising of prices for fossil fuels. Obtaining energy from renewable energy sources becomes thus a valuable investment, for consumers as well as for industrial plants of high capacity. The favorable conditions for producing energy from alternative sources are determined by the legislation in force and the European funds which encourages the production of renewable energy from biomass, as well as the use of solar energy, wind energy, geothermal and hydro energy.

The use rhythm of the renewable sources will continue to increase, so that the production of electrical energy from these sources in 2020 will represent $38 \%$. The biomass is regarded as alternative energy source of wide scope, widely spread worldwide and presents different forms which may be used for green energy production.

The wood covers nowadays more than $10 \%$ of the demand of primary energy in many countries from Asia, Africa and Latin America and in some countries in Europe (Sweden, Finland, Austria)[6].

In Europe, the renewable energy has a rate of annual increase of primary energy with an average of 3,4\% during 1990-2005. At the worldwide level, the biomass is the sole energy source which can be used in future as an accessible renewable source.

The chemical composition of the biomass, respectively for plants is $25 \%$ lignin and $75 \%$ carbohydrates (celluloses and hemi-celluloses) or saccharides. One of the most important carbohydrates is cellulose. Lignin appears in plants as something like glue having a role of adhesion between the usual structures of resistance, which ties the cellulosic molecules between them [7].

During the last centuries the humanity has learnt to obtain fossil types of biomass, especially, as coal. Fossil fuels present the result of the very slow chemical reaction of transformation the poly saccharides in chemical compounds resembling the lignin fraction.

In some developed countries, the biomass is used intensively enough. Sweden plans for the future the increase of the biomass volume used concomitant with the closing of nuclear - electrical and thermo - electrical plants, which uses fossil fuel coal type or methane gas. In U.S.A there are installations with a total capacity of 90000 MW which function, where the biomass burns with the purpose of obtaining electrical energy. The biomass may assure over $20 \%$ from the energetic necessities of the country. At the beginning of the 1980s, almost 1.3 billion people provided the necessity in fuels based on decreasing the forest reserves, by massive cuttings[8].

The biomass is the assembly of non-fossil organic materials, where there are registered: wood, vegetal oils and wastes in the forest, agricultural and industrial field, but also the cereals and fruits, from which ethanol may be produced. Similar to the energy obtained from fossil fuels, the energy produced from biomass comes from the solar energy stored in plants, through the photosynthesis process with the help of light.

The main difference between the two forms of energy is that the fossil fuels could not be extracted and transformed in energy useable only after thousands of years, while the biomass energy is renewable, being used 
each and every each (if some clear rules are observed regarding their sustainability)[9].

Supplying energy from biomass took off starting the 2000, and in 2010 this field has already supplied 280 TWh of electrical energy at the global level, which equals $1.5 \%$ of electrical energy supplied worldwide. Presently the biomass continues to play an important role in the countries which are not OECD member (The Organization for Economic Co-operation and Development) and represents the main source which provides the energetic necessary. Presently, the countries in developing process assure their energy necessary through sources such as biomass using central heating with a low rating of $10-15 \%$. Taking into consideration these aspects, it becomes necessary to supply the energetic market with fuels and thermal installations with high rating, thus the biomass should become a competitive source on the energetic market.[10]

Romania must encourage the companies and citizens in order to invest in alternative energy sources. Therefore, the electrical energy balance produced from renewable resources of energy, in comparison to the gross natural consumption of electric energy must reach $33 \%$ until 2020. The main renewable energy sources in Romania could be: biomass, solar, wind and geothermal energy [11].

The main purpose of the paper is to make a comparative study between the physical and energetic proprieties of the four types of briquettes (wheat and rape briquettes, 2017 wheat briquettes, 2018 wheat briquettes, lucerne briquettes). Among the physical proprieties, the individual density and humidity was analyzed, among the energetic proprieties the caloric power and ash content were analyzed[12].

\section{Materials and methods}

There were analyzed four types of briquettes: wheat and rape briquettes, 2017 wheat briquettes, 2018 wheat briquettes, lucerne briquettes, in order to determine which are better to be used in combustion.

In order to determine the density, the classical method to determine their weight and volume was used. The samples, over 20 pieces of each type, were taken from test tubes and the ends were cut perpendicularly lengthwise, in order to obtain a clear length. The cylindrical shape of briquettes was chosen because, only for this type the method to determine the perpendicular compression is applied, and the volume is easily determined, as volume of a smooth circular cylinder. The briquettes were weighted using an electronic scale TP KERN EW 1500-24 with precision of 0,1 grams. As well, it was determined the average diameter of the briquettes, as average mean in three points (at the ends and middle), for two perpendicular diameters. The determining relation of density was as follows:

$\rho=\frac{4 m}{\pi D_{m}^{2} l} \quad\left[\mathrm{~g} / \mathrm{cm}^{3}\right]$

where: m-briquette weight, in g;
$\mathrm{D}_{\mathrm{m}}$ - average diameter of the briquettes, in $\mathrm{mm}$;

1- test sample length, in $\mathrm{mm}$.

The moisture content determined for the four types through the classical method of weighting-dryingweighting for briquettes was $8 \%$ [13-15].

The caloric power represents the quantity of heat resulted while burning a weight unit of fuel. There were performed 2 determinations for the caloric power for briquettes: superior caloric power (when the water vapors condensate, relieving evaporation heat) and the inferior caloric power (when a part of the heat for water evaporation is lost). The inferior caloric power is the difference between the superior caloric power and the quantity of heating relieved for the water evaporation from the burning gas the devices used to determine the caloric power of the four types of briquettes is the calorimetric bomb XRY-1C (made in China) (Fig 1)[16$18]$.

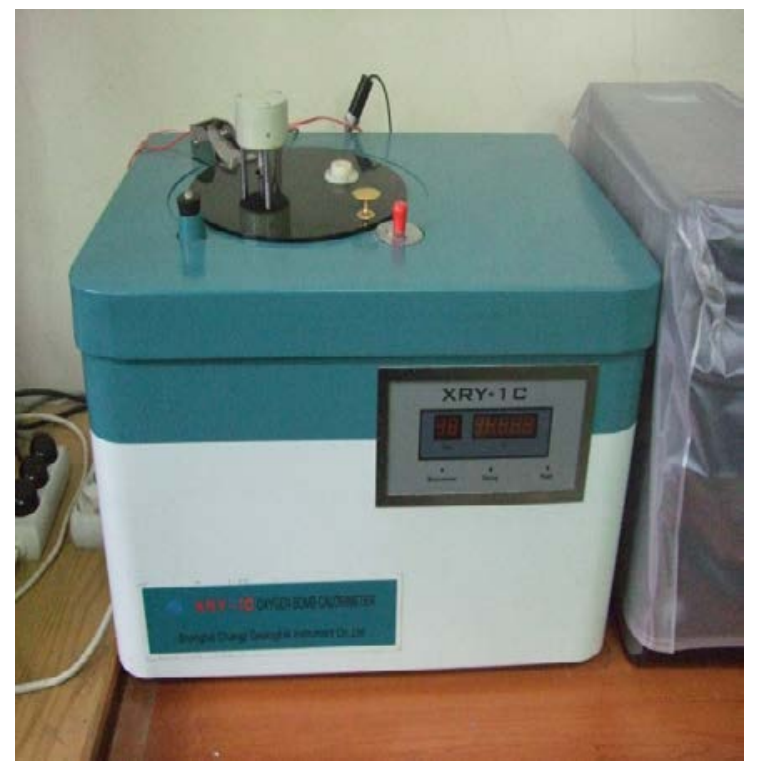

Fig. 1. Calorimetric bomb XRY-1C

Determining the caloric power of fuels is researched worldwide. Until the present there are a series of manners to determine the caloric power for wooden species, on an experimental manner as well as empiric equations. For the first time, the calorimeter Junkers type was used, which determines the caloric power for gaseous fuels. The method consists in burning out a known quantity of gas and the practical transmission of the heat losses relieved in the burning process, a water flow which circulates through the calorimeter. For this purpose, a quantity of fuel measured is burnt with the help of a gas burner or burner. The gas resulted from burning is cooled to the temperature of the environment by a powerful water flow. The weight of water, the temperature variation, the weight of condensed vapors from the burning products are measured and thus the burning superior heat is determined, as well as the inferior one.

For combustible materials with high content of water and hydrogen, such as wooden biomass, two types of caloric powers may be identified, respectively the superior caloric power and the inferior caloric power. The superior caloric power cannot be used in practical 
manner. Because the water vapors evacuate outside the vent and only the inferior caloric power remains, which is the most important and leads to the assurance of the energetic necessary.

Determining the caloric power implies going over three phases: initial phase, main phase, final phase. The initial phase represents the determination of temperature variation of water in the interior of the calorimetric container, because of the heat exchange with the exterior before the burning. At the end of the initial phase the burning of the samples extracted from briquettes begins.

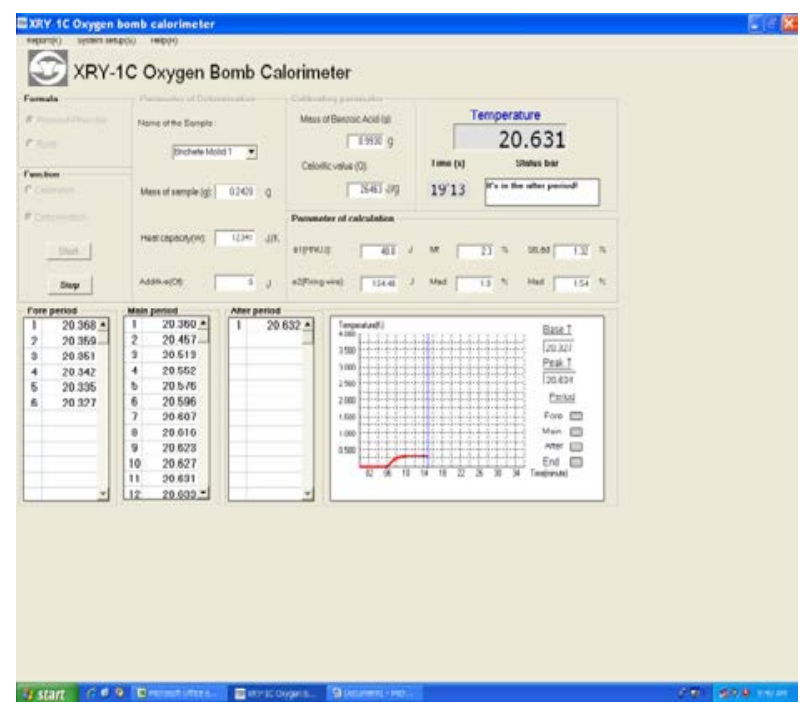

Fig. 2. The image of the computer soft for the calorimeter with explosive burning for the determination of the caloric power The superior caloric power is determined with the relation:

$Q_{s}=\frac{K \cdot\left(\mathrm{t}_{\mathrm{f}}-\mathrm{t}_{\mathrm{i}}\right)}{m}-q_{s}$

where:

$\mathrm{K}$ is the calorimetric factor, expressed in $\mathrm{kJ} /$ degree Celsius;

$t_{f}$ - final value of the temperature, expressed in ${ }^{\circ} \mathrm{C}$;

$\mathrm{t}_{\mathrm{i}}$ - initial value of temperature, in ${ }^{\circ} \mathrm{C}$;

$\mathrm{q}_{\mathrm{s}}$ - heat consumed for the burning of incandescent wire in the gersdorffite and the cotton wore, for the initiation of burning, expressed in $\mathrm{kJ} / \mathrm{kg}$;

$\mathrm{m}$ - fuel sample weight, in $\mathrm{kg}$.

In order to determine the ash content of briquettes, it was used the general method of standardized determination (ASTM D2866-11, 2012). According to this method, material is minced and dried until $0 \%$ humidity at a temperature of $650{ }^{\circ} \mathrm{C}$ in a laboratory stove, at least for 3 hours. The advanced burning operation is performed on a high temperature proof metallic pot, and the weighting is performed on an analytical scale with a precision of 3 decimals.

When determining the ash content, it will be taken into account that the sample is completely dried and the pot weight clean and empty.

\section{Results and discussion}

The density values for the four types of briquettes are: $937 \mathrm{~kg} / \mathrm{m}^{3}$ - wheat and rape briquettes, $1094 \mathrm{~kg} / \mathrm{m}^{3}-2018$ wheat briquettes, $1052 \mathrm{~kg} / \mathrm{m}^{3}-2017$ wheat briquettes, $983 \mathrm{~kg} / \mathrm{m}^{3}$ - lucerne briquettes.

In figure 3 there are presented individual density values for the four types of studied briquettes.

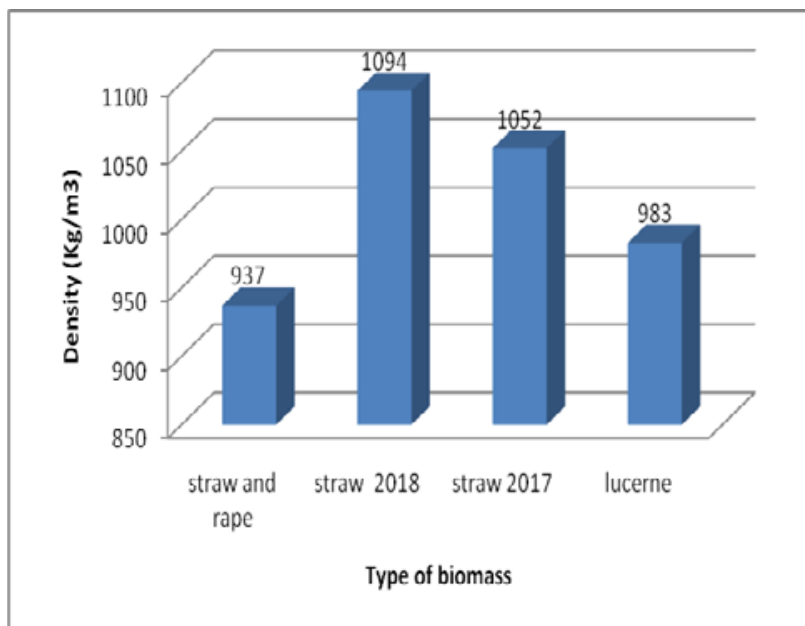

Fig. 3. The values of individual density for the four types of briquettes

The values of the superior caloric power for the four types of briquettes are: $19458 \mathrm{~kJ} / \mathrm{kg}$ wheat and rape briquettes, $17689 \mathrm{~kJ} / \mathrm{kg} 2018$ wheat briquettes, 17661 $\mathrm{kJ} / \mathrm{kg} 2017$ wheat briquettes, $17989 \mathrm{~kJ} / \mathrm{kg}$ alfalfa briquettes.

In figure 4 it is presented the values of the superior caloric power for the four types of briquettes.

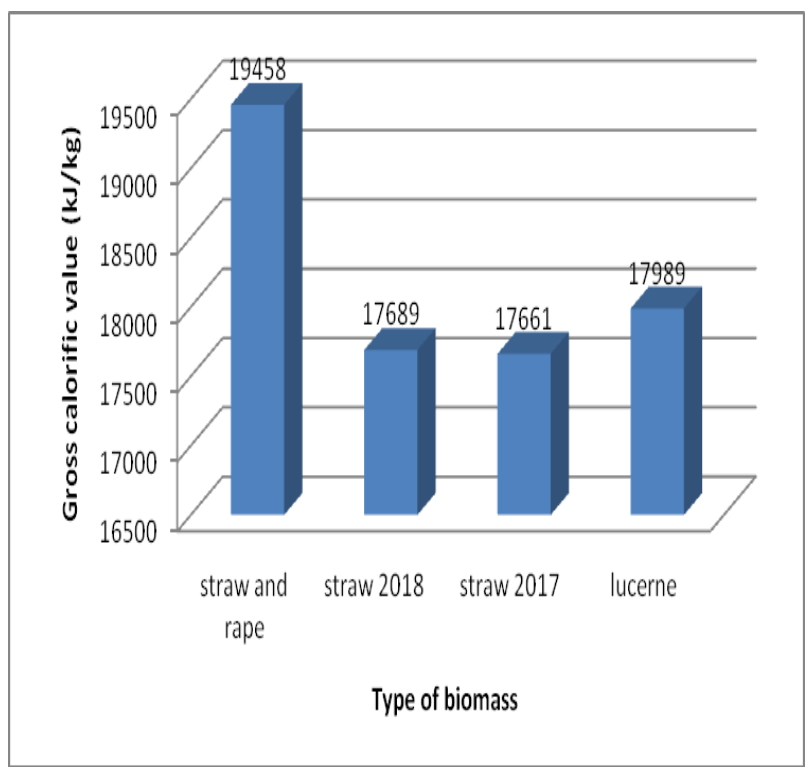

Fig. 4. The values of superior caloric power for the four types of briquettes

In figure 5 there are presented the values of the ash content for the four types of briquettes. 


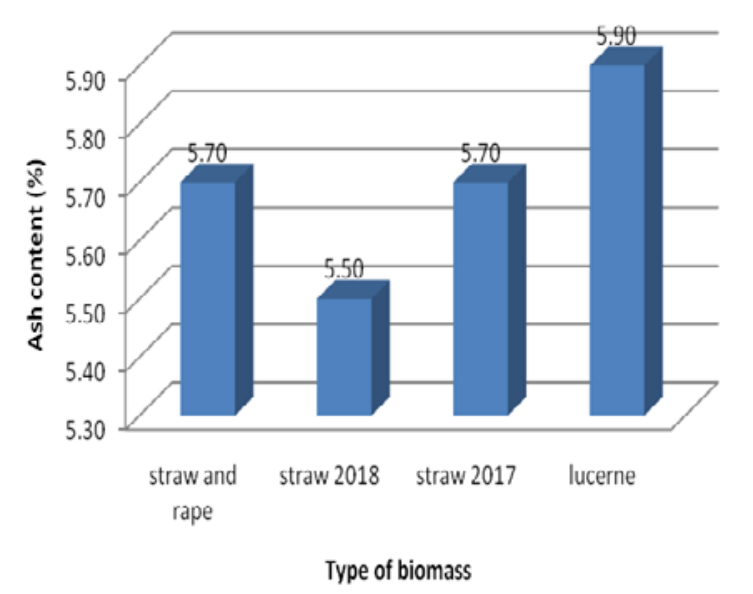

Fig. 5. The values of the ash content for the four types of briquettes

\section{Conclusions}

Briquettes have an exceptional thermal capacity; therefore, they retain heat for a much higher period of time and keep the temperature high within the focal point, allowing a facile burning of the new introduced briquettes.

The biomass represents a renewable source of energy. This does not contribute to the problem of environment changing, because it recycles the carbon dioxide in the atmosphere.

Wheat and rape briquettes have the best caloric capacity, while the 2017 wheat briquettes have the lowest caloric capacity, among the four types of analyzed briquettes. The main conclusion of the paper refers to the use of these briquettes and there is stated that they are used as well as other briquettes resulted from wood or other wooden materials. This thing is possible due to the good characteristics of briquettes, equivalent to the ones made of other materials.

\section{References}

1. J.P. Boutin, G. Gervasoni, R. Help, K. Seyboth, P. Lamers, M. Ratton et al. Alternative Energy Sources in Transition Countries. The Case of Bio-energy in Ukraine. Environ Engineering and Management Journal , vol.6, nr.1, pp.3-11 (2007)

2. A.V. Bridgwater, Review of Fast Pyrolysis of Biomass and Product Upgrading, Biomass bioenergy, vol. 38, pp. 68-94 (2012)

3. C.Ciubota-Rosie, M. Gavrilescu, M. Macoveanu Biomass-an Important Renewable Source of Energy in Romania, Environ Engineering and Management Journal, vol.7, pp.559-568 , (2009)

4. A. Demirbas Resource Facilities and Biomass Conversion Processing for Fuels and Chemicals, Energy Conversion Management, vol. 42, nr. 11, pp. 1357-1378, (2011)
5. A.M. Garcia, B.M.J. Barcia, J.A. Hernandez Preparation of active Carbon from a Comercial Holm-Oak Charcoal: Study of Micro and Mesoporosity, Journal Wood Science and Technology, vol. 37, nr. 5, pp. 499-509 (2008)

6. D. Gavrilescu Energy from biomass in pulp and paper, Environmental Engineering and Management Journal, vol. 7(5), pp.537-546, (2008)

7. M. Gavrilescu Biomass Power for Energy and Sustainable Development, Environmental Engineering and Management Journal, vol. 7(5), pp.617-640, (2008)

8. N. Kaliyan, R.V. Morey Factors Affecting Strength and Durability of Densified Biomass Product, Biomass Bioenerg, vol. 33, nr. 3, pp. 379-359, (2009)

9. T. Kuhlman, V. Diego, E. Koomen Exploring the potential of reed as a bioenergy crop in the Netherlands, Biomass Bioenergy, vol. 55, pp.41-52, (2013)

10. J. Lako, J. Hancsok, T. Yuzhakova, G. Marton, A. Utsai, A. Redey, Biomass and Bioenergy, vol. 40, pp. 63-73, (2012)

11. A. Lunguleasa Compaction coefficient of wooden briquettes used as renewable fuel, Environmental Engineering and Management Journal, vol.10, nr. 9, pp.1263-1268, (2011)

12. A. Lunguleasa The compressive strength of wooden briquettes used as renewable fuel, Environmental Engineering and Management Journal, vol. 9, pp.977-982, (2010)

13. C. Okello, S. Pindozzi, S. Faugno, L. Boccia Bioenergy potential of agricultural and forest residues in Uganda, Biomass Bioenergy, vol. 56, pp. 515-525, (2013)

14. N. A. Pambudi, K. Itaoka, A. Chapman, N. D. Hoa, N. Yamakawa Biomass energy in Japan: Current status and future potential, International Journal of Smart Grid and Clean Energy, vol. 6, no. 2, pp. 119126 (2017)

15. J. Swithenbank, Q. Chen, X. Zhang, V. Sharifi, M. Pourkashamiani Wood would burn, Biomass and bioenergy, vol.3, (2011)

16. J.Tanchuling, R. De Leon Solid fuel characterization of torrefied coconut shells in an oxidative environment, International Journal of Smart Grid and Clean Energy, vol. 7, no. 2, pp. 145-151 (2018)

17. O. Teuch A. Hofeanuer, F. Troger, J. From Basic properties of specific wood based materials carbonised in a nitrogen atmosphere, Wood Science Technology Journal, vol.38, nr.3, pp.323-333, (2004)

18. V.K. Verna, S. Bram, J. de Rucky Small Scale Biomass Systems: Standards, Quality, Labeling and Market Driving Factors-An Outlook Biomass Bioenerg, vol.33, nr.10, pp. 1393-1402, (2009) 